\title{
An unpublished poem of Nicephorus Blemmydes.
}

Codex Baroccianus 131 (saec. XIV), fol. $171^{\mathrm{v}}-172^{\mathrm{r}}$, contains the following curious poem, consisting of 122 (not, as Coxe says, 162) political verses, by Nicephorus Blemmydes:

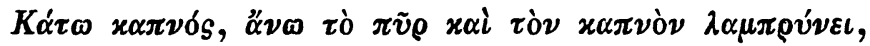

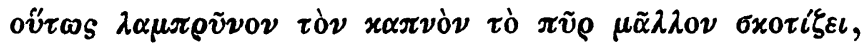

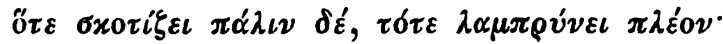

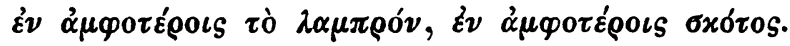

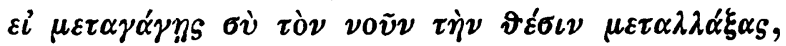

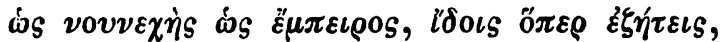

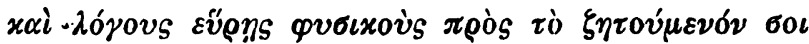

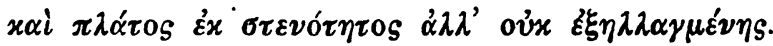

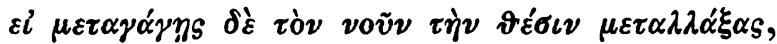

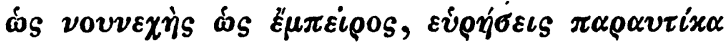

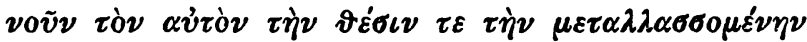

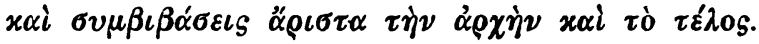

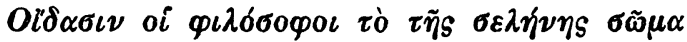

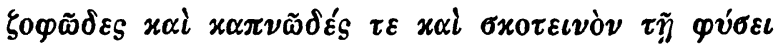

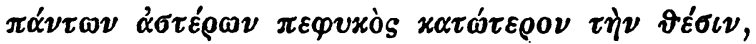

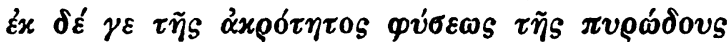

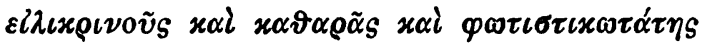

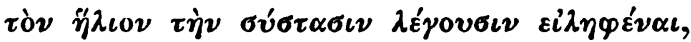

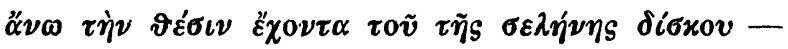

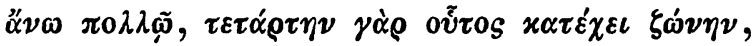

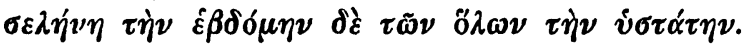
$K \alpha \pi \nu \tilde{\delta} \delta \varepsilon$ o

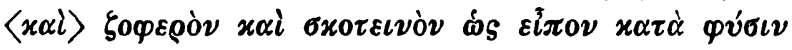

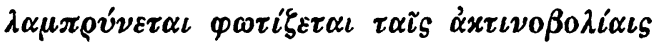

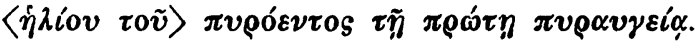

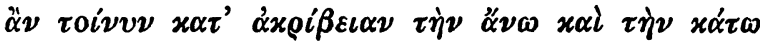

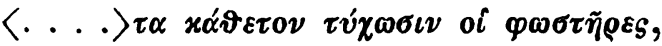

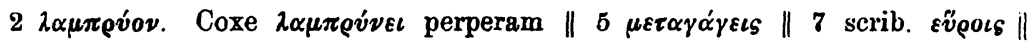
$9 \mu \varepsilon \tau \alpha \gamma \alpha \dot{\gamma} \gamma \varepsilon \iota$ || $24 \lambda \alpha \mu \pi \rho \dot{v} \eta \tau \alpha \iota \mid$ | $\omega \tau i \zeta \eta \tau \alpha \iota$ 


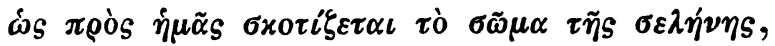

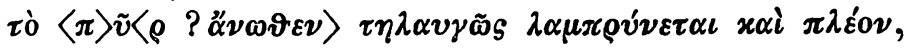

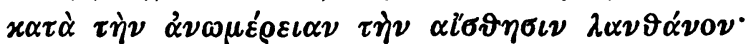

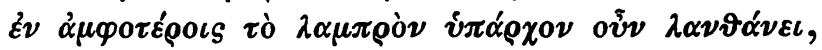

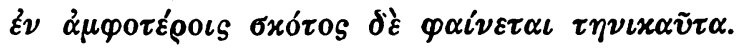

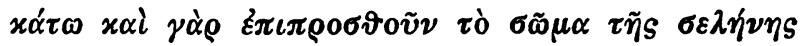

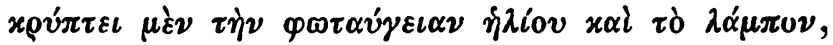

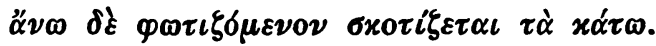

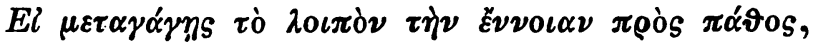

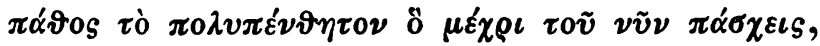

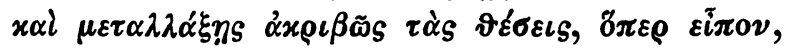

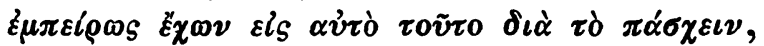

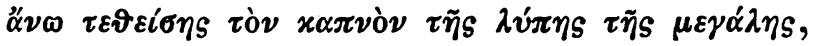

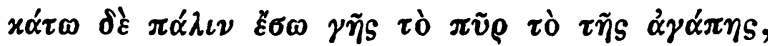

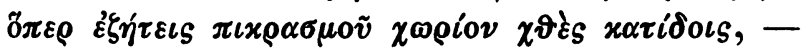

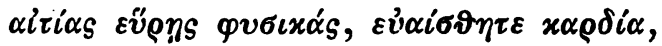

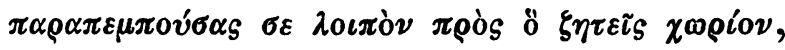

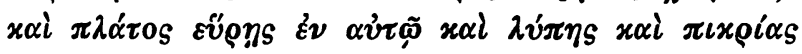

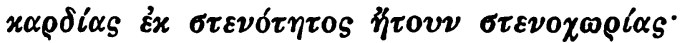

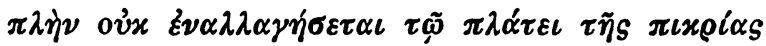

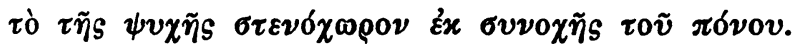

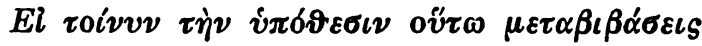

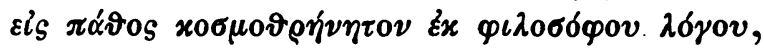
50

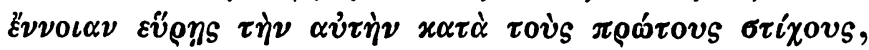

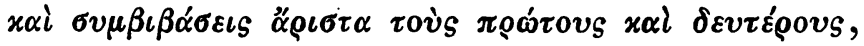

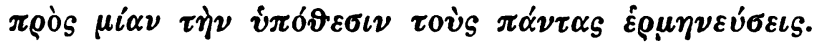

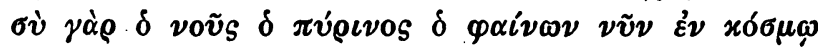

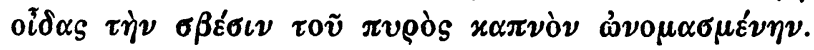

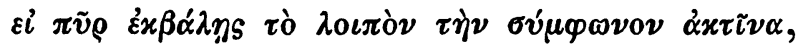

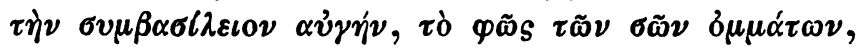

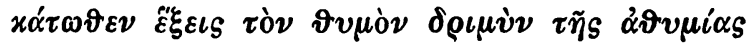

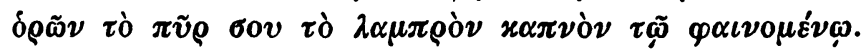

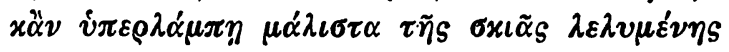

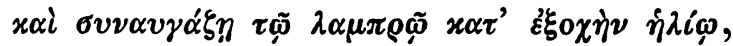

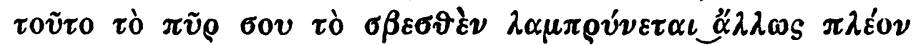

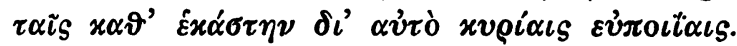

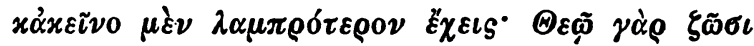

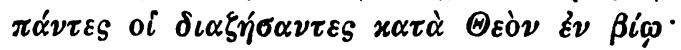




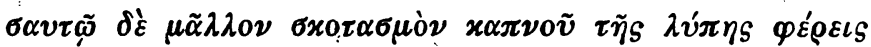

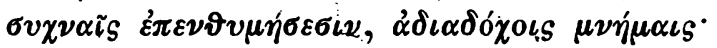

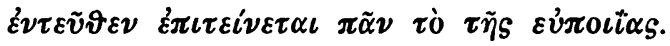

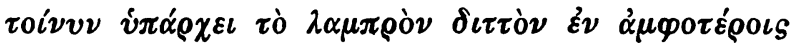

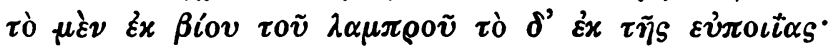

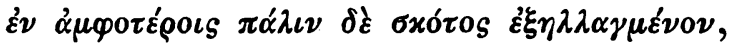

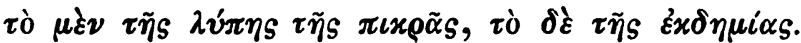

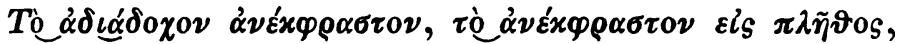

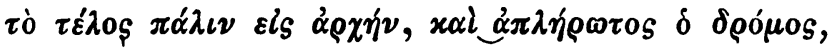

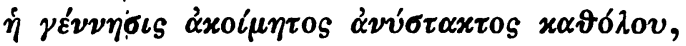

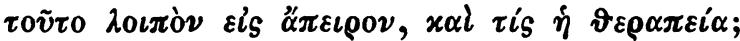

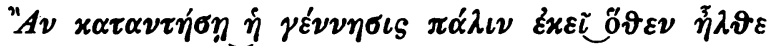

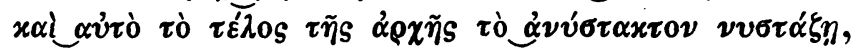

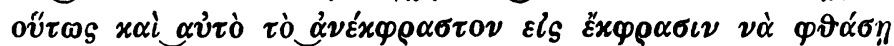

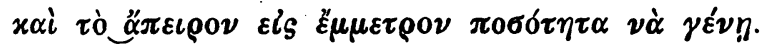

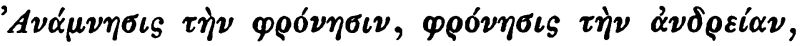

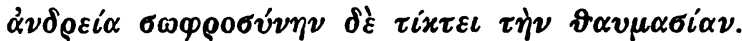

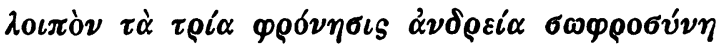

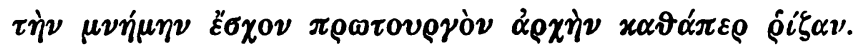

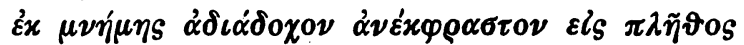

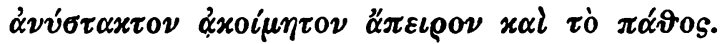

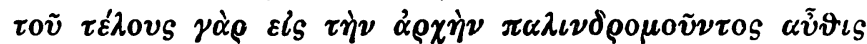

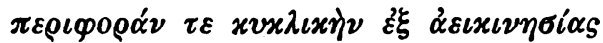

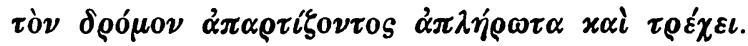

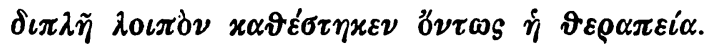

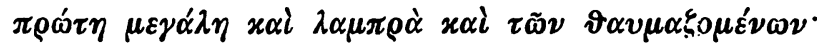

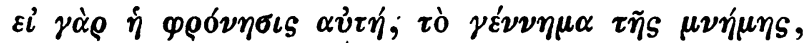

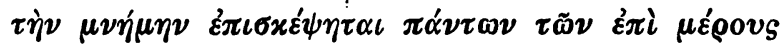

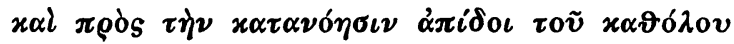

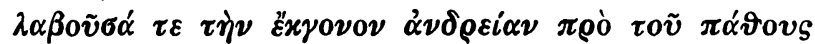


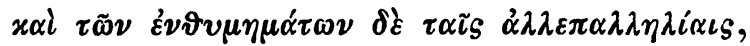

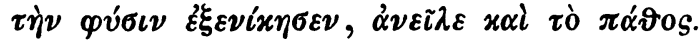

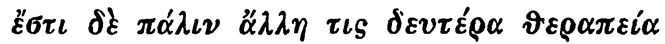

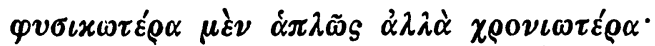

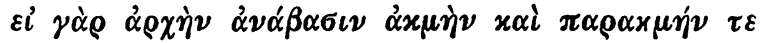

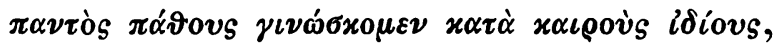

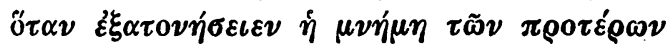

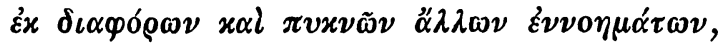




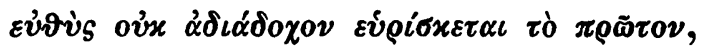

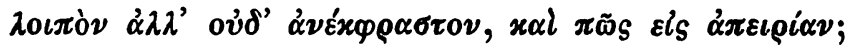

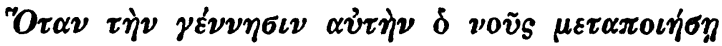

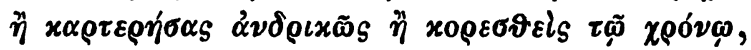

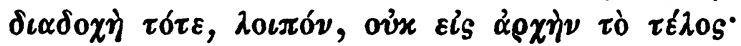

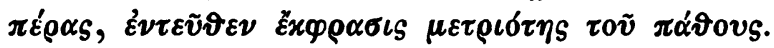

110

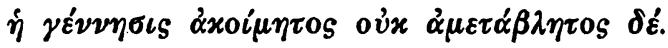

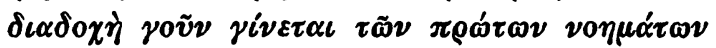

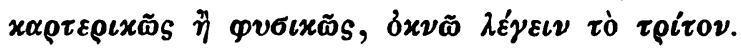

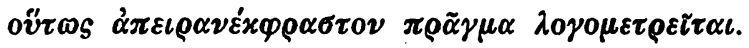

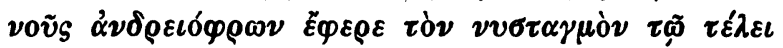

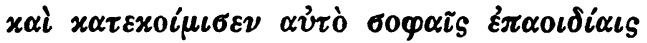

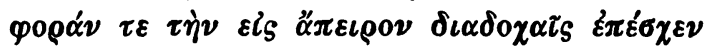

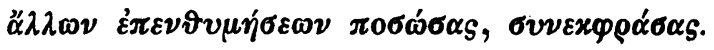

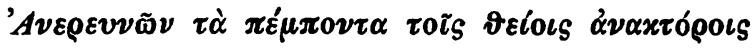

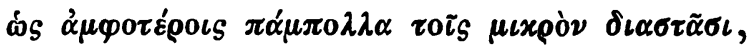

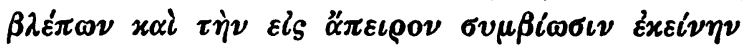

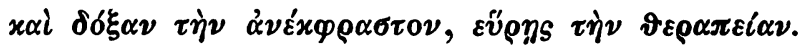

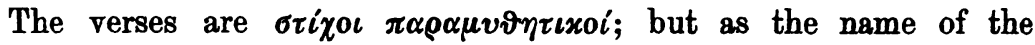
person, whose affliction Blemmydes desires to alleviate by this pedantic and frigid consolation, is not mentioned, it was some time before I could reach a definite conclusion as to its purport and occasion. In the first place, it is meant for an Emperor. I infer this from v. 54

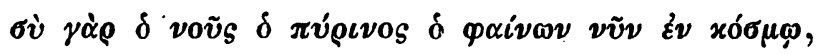

taken in conjunction with $\sigma v \mu \beta \alpha \sigma i \lambda \varepsilon \iota 0 \nu$ in v. 57. In the second place, the sorrow for which the Emperor needed solace was the loss of his wife. This may be inferred from vv. 56, 57

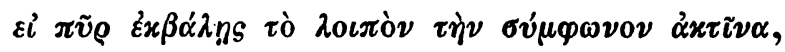

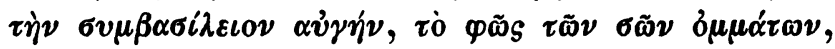

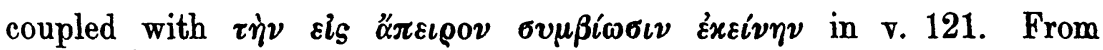
these two data there can only be one conclusion. The verses were addressed to John Vatatzes on the occasion of the death of the Empress Irene, a lady whose virtue and discretion have been recognised by history ${ }^{1}$ ), and to whom there is every reason to suppose that the

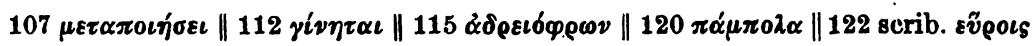

1) Cf. Acropolites p. 67-8, Anonymi Synopsis Chronica (ed. Sathas) p. 485,

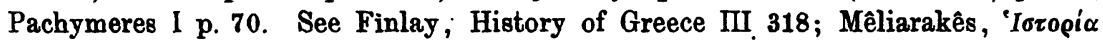

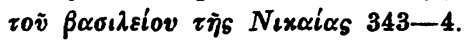


Emperor was deeply attached. Irene died in 1241, and Blemmydes doubtless wrote this extraordinary effusion shortly (but not perhaps immediately) after the event.

The passage (wv. 26-35) in which the phenomenon of a solar eclipse is adduced to illustrate the close connexion of light and darkness in nuture has a certain interest. A solar eclipse had occurred on June 3, 1239, and has an association with the Empress Irene. At that time she was at Periclystra, near Smyrna, and, being inquisitive of knowledge, she asked George Acropolites ${ }^{1}$ ), then a young man of 21 years, whether he could explain the cause of the eclipse, which was naturally a subject of conversation. Acropolites, though he had not yet adranced far in his scientific studies under the tutelage of Blemmydes, replied that it was the interposition of the moon between earth and sun. A discussion ensued, and the arguments of a certain courtier, who confidently disputed the statement of Acropolites, so fully persurded Irene that she was betrayed into calling the young man a fool. But repentant in a moment of her hasty word, she turned to the Emperor and said: "I was wrong to call him a fool". "It matters not", said John "he is only a boy". But she said: "It is not right to use such a term to one who advances scientific theories". The eclipse which occasioned this interesting incident was afterwards generally regarded as a divine premonition of the august lady's death. We can hardly be wrong in supposing that Blemmydes considered an illustration drawn from an eclipse of the sun as specially appropriate and felicitous in a poem composed on the occasion of a death which had been thus foretold.

The poem may be divided into two parts. The theme of the first part (1-72) is that fire and smoke, darkness and light, are found together and interpenetrate each other. The death of Irene seems the extinction of light which was the light of her husband's eyes (57); the fire has apparently become smoke (59), but only to become more brilliant (64); while on the other hand her consort's light darkened by

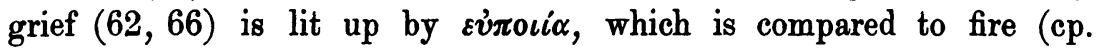
Shakespeare "As shines a good deed in a naughty world"). The second portion (73-118) points out two remedies for the continuous

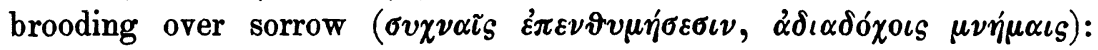
1) brave resistance, 2) the healing power of time. The last four lines add a final consolation, the hope of reunion in a future life.

There is a point of some interest in v. 72. Blemmydes says that

1) Who tells the story, loc. cit. 


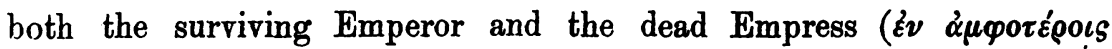
$69,71)$ have each light as well as gloom in their existences. He has the light of $\varepsilon \dot{v} \pi 0 i_{i} \alpha$ beside the darkness of his bitter grief; she has

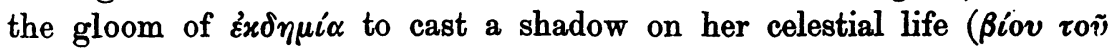
$\lambda \alpha \mu \pi \rho \circ \tilde{v} 70)$. It is thus suggested that the bliss of the departed in heaven may be somewhat overcast by gloom, through the absence of the-beloved friends whom they have left behind on earth, - the idea of Rossetti's poem and picture "The Blessed Damozel".

I subjoin a few notes.

1-4. The application of these lines is explained by ₹v. 56-72.

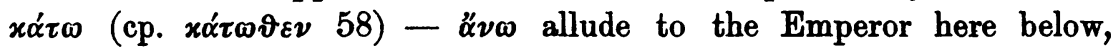
the Empress in heaven.

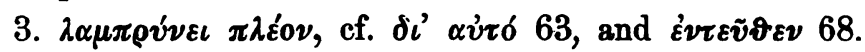

8. Cf. $45-48$.

13 sq. Cf. Blemmydes, Epitome Physica, capp. 26 and 27 (in Migne, P. G. vol. 142).

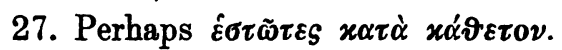

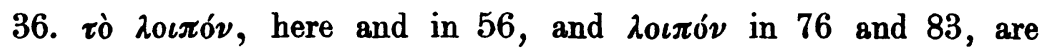
used in the sense which $\lambda o \iota \pi v^{\nu}$ bears in Modern Greek (much like English "Well —", German "also").

37. $\mu \varepsilon x \varrho \iota \tau o \tilde{v} \nu \tilde{v} \nu$. The form of expression suggests that some time had elapsed since Irene's death.

42. $\chi \vartheta \vartheta \varepsilon$ s. The poem then was written on the day following a conversation of Blemmydes. with the Emperor on the subject of his bereavement.

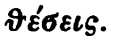

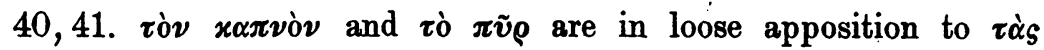

41. $\varepsilon \sigma \omega \gamma \tilde{\eta} s$, in the tomb.

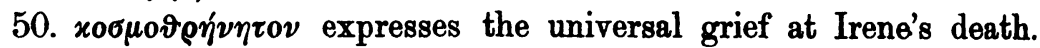

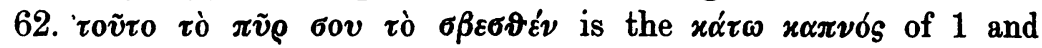

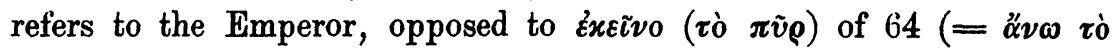
$\pi \tilde{v} \varrho$ of 1) referring to the Empress.

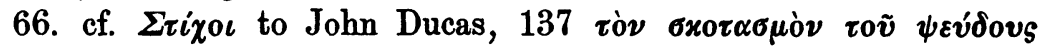
(ed. Heisenberg p. 105).

68. The idea is that the Emperor's sorrow will have the effect of

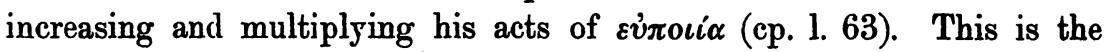

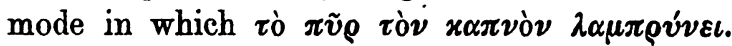

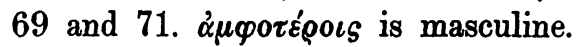

73. The second argument, beginning here, takes up the phrase $\dot{\alpha} \delta\left\llcorner\alpha \delta o ́ x 0 \iota s \mu \nu \eta_{\mu \alpha \iota s}\right.$ in 67, and thus connects itself with the first. The 
problem how the bereaved husband is to escape from brooding memories is very frigidly stated as a psychological puzzle.

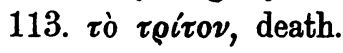

118. $\pi 0 \sigma \omega ́ \sigma \alpha s$, cf. 80.

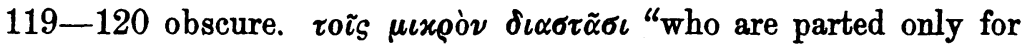
a short space of time".

Dublin.

J. B. Bury.

\section{Plutarchische Reminiscenzen bei Michael Akominatos.}

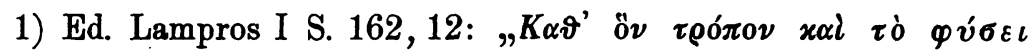

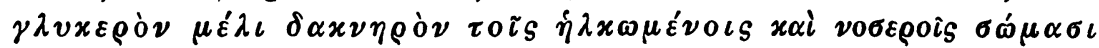

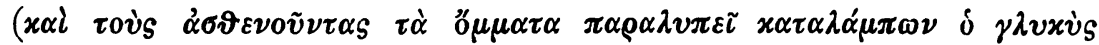

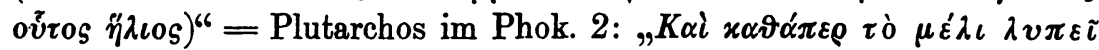

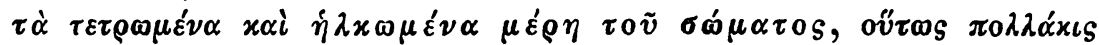

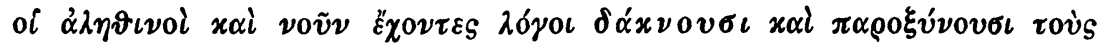

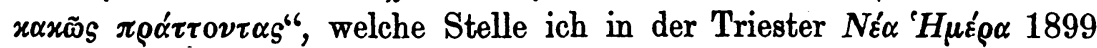
Nr. 1297 als Quelle für Michael Glykas, Krumb. S. 449, V. 45-46:

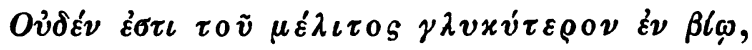

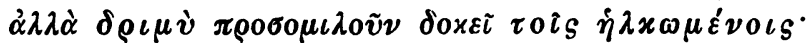

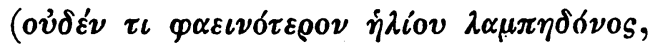

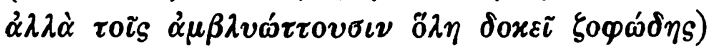

nachgewiesen habe.

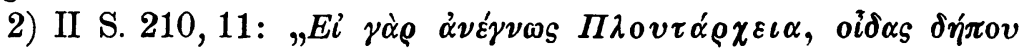

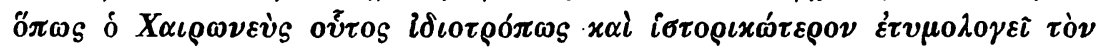

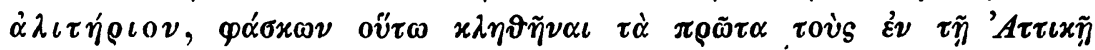

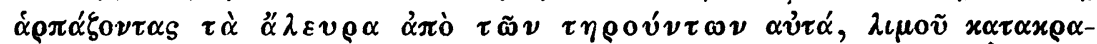

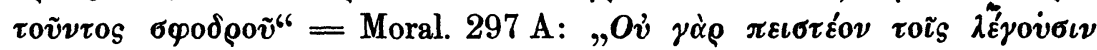

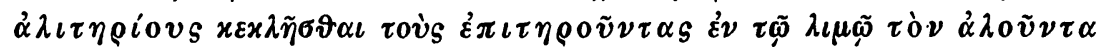

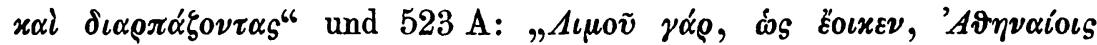

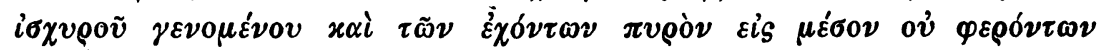

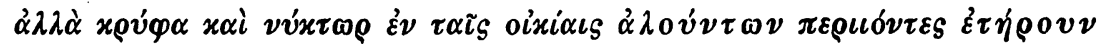

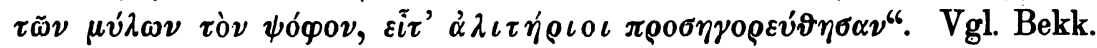

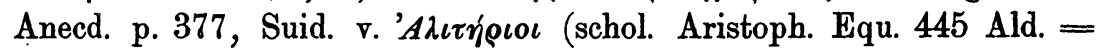
Dübn. p. 406).

Saloniki, 1./14. Juni 1900.

P. N. Papageorgiu. 